$\mathrm{Ab}$ Mitte der 1950er-Jahre trat er als Publizist in Erscheinung, der sich weniger mit politischen Themen, sondern mit seinen zahlreichen Büchern insbesondere mit wissenschaftsgeschichtlichen und naturwissenschaftlich-philosophischen Problemen auseinandersetzte. Schließlich veröffentlichte Koestler 1983 eine Zusammenfassung seiner autobiografischen Werke, die bis zum Jahr 1941 reichten. ${ }^{308}$ Kurz nachdem er nach schwerer Krankheit gemeinsam mit seiner dritten Ehefrau Cynthia den Freitod wählte - die Leichen wurden am 3. März 1983 in ihrer Wohnung in London aufgefunden -, erschien die deutsche Ausgabe der gemeinsamen Lebensgeschichte bzw. "Liebesgeschichte« des Ehepaares, die die Jahre von 1940 bis 1956 zum Inhalt hatte. ${ }^{309}$

\title{
4.4 George Orwell
}

In seinem unter dem Titel Die Pilgerfahrt eines Rebellen im Monat erschienenen Nachruf, anlässlich des Todes seines Freundes am 21. Januar 1950, schrieb Koestler, dass Orwells Leben »eine einzige konsequente Folge von Revolten gegen die soziale Tyrannei im allgemeinen« war. ${ }^{310}$ Es entsprach Orwells früh ausgeprägtem Selbstverständnis, gegen jedwede soziale und politische Ungerechtigkeiten zu kämpfen. Er avancierte aufgrund persönlicher Erfahrungen zum Prototypen des antitotalitären Intellektuellen und warf seinen ehemaligen Mitstreitern vor: „Die Sünde beinahe aller Linken von 1933 an war es, dass sie antifaschistisch zu sein suchten, ohne antitotalitär zu sein. « $^{311}$

Orwell wurde am 25. Juni 1903 unter seinem richtigen Namen Eric Arthur Blair als zweites Kind eines britischen Kolonialoffiziers in Bengalen geboren, wuchs allerdings in England auf. ${ }^{312}$ Er besuchte in seiner Kindheit eine Kirchenschule und die Privatschule St. Cyprians in Eastbourne (Sussex) und ging im Alter von 14 Jahren von 1917 bis 1921 als Stipendiat auf das weltberühmte Eton-College. 1922 zog es ihn nach seinem Schulabschluss in die britische Kolonialpolizei von Burma. Nach fünfähriger Dienstzeit für die Indian Imperial Police in Burma kehrte er als Gegner des Kolonialismus und Imperialismus nach England zurück und lehnte fortan als unabhängiger Sozialist jedwede soziale und politische Unterdrückung ab. 1933 erschien unter dem Pseudonym George Orwell das erste fertiggestellte Buch Down and Out in London and Paris, in dem der Autor - in der Tradition des englischen Realisten Charles Dickens stehend - seine Erfahrungen mit den von Armut und Hunger geprägten Verhältnissen in den Elendsvierteln von Paris sowie den Armenhäusern von London schilderte. ${ }^{313}$ Mit seinen negativen Kolonialerfahrungen setzte er sich in dem 1934 in den USA veröffentlichten Band Burmese Day auseinander. ${ }^{314}$ Nach der Veröffentlichung der bei-

308 Als Zeuge der Zeit. Das Abenteuer meines Lebens, Bern/München 1983.

309 Arthur und Cynthia Koestler, Auf fremden Plätzen. Bericht über die gemeinsame Zeit, Wien u. a. 1984.

310 Arthur Koestler, Die Pilgerfahrt eines Rebellen, in: Der Monat 2 (1950), H. 18, S. 563-565, hier S. 563.

311 Zit. n. Howald, George Orwell, S. 8.

312 Siehe grundsätzlich die Biografien Bernard Crick, George Orwell. Ein Leben, Frankfurt a. M. 1984; Jeffrey Meyers, Orwell. Wintry Conscience of a Generation, New York 2000; Gordon Bowker, George Orwell, London 2003 sowie D. J. Taylor, Orwell: The Life, London 2003.

313 George Orwell, Down and Out in London and Paris, London 1933 (dt. Ausg.: Erledigt in Paris und London, Zürich 1978).

314 Ders. Burmese Day, New York 1934 (dt. Ausg.: Tage in Burma, Zürich 1982). 
den Romane A Clergyman's Daughter ${ }^{315}$ und Keep the Aspidistra Flying ${ }^{316}$ stand die soziale Frage explizit in dem 1937 erschienenen Buch The Road to Wigan Pier im Vordergrund. ${ }^{317}$ Insbesondere diese Reportage über die wirtschaftliche Depression in den nordenglischen Industriegebieten beschrieben "seine Bekehrung zum Radikalismus und zum äußersten Flügel einer theoretisierenden Gesellschaftskritik«. ${ }^{318}$

Der sechsmonatige Aufenthalt in Spanien 1937 als Freiwilliger auf republikanischer Seite, d.h. in einer Einheit der POUM, stellte den »Zweiten Wendepunkt« in Orwells Leben dar. Die totalitären Erfahrungen schilderte er in Hommage to Catalonia. ${ }^{319}$ Nachdem er Borkenaus The Spanish Cockpit in einer Buchbesprechung gewürdigt hatte, rezipierte Orwell auch dessen Studien The Communist International (1938) und The Totalitarian Enemy (1940). Beide Bücher übten nachhaltigen Einfluss auf ihn aus und Orwell veröffentlichte zwei »begeisterte Rezensionen«. ${ }^{320}$

Orwell, der frühzeitig publizistisch gegen Hitler Stellung bezog, ${ }^{321}$ arbeitete während des Zweiten Weltkrieges, nachdem seine Bemühungen, kriegstauglich geschrieben zu werden, gescheitert waren, als Textredakteur beim indischen Dienst der BBC. Nach seiner Kündigung begann er Ende 1943 eine Mitarbeit als Kolumnist bei der linken Wochenzeitschrift Tribune; unter anderem setzte Orwell sich in seinen gesellschaftskritischen Beiträgen mit der »Diskriminierung Farbiger « auseinander. ${ }^{322} \mathrm{Zu}$ dem setzte er sich mit der destruktiven Rolle der zeitgenössischen Phänomene des Antisemitismus und des Nationalismus auseinander und ging hierbei auch auf die nationalsozialistischen Judenverfolgungen ein. ${ }^{323}$

Gemeinsam mit Koestler versuchte Orwell seit Ende 1944 in der Zeitschrift Horizon ein Netzwerk von Intellektuellen aufzubauen, das zum Ziel hatte, die kulturelle und organisatorische Infiltration in England durch die Kommunistische Partei abzuwehren. In diesem Zusammenhang wurde Ende 1945 von Orwell und Koestler die League for the Defense of Democracy gegründet mit der Absicht, die britische Menschenrechtsliga von »fellow-travellers« sowie Kommunisten zu säubern. ${ }^{324}$

315 Ders., A Clergyman's Daughter, London 1935 (dt. Ausg.: Eine Pfarrerstochter, Zürich 1983).

316 Ders., Keep the Aspidistra Flying, London 1936 (dt. Ausg.: Die Wonnen der Aspidistra, Zürich 1983).

317 Ders., The Road to Wigan Pier, London 1937 (dt. Ausg.: Der Weg nach Wigan Pier, Zürich 1982).

318 Mitteilung der Redaktion des Monat in: Der Monat 1 (1949), H. 5, S. 111.

319 Orwell, Homage to Catalonia.

320 Bernard Crick, George Orwell. Ein Leben, S. 456.

321 George Orwell, Mein Kampf von Adolf Hitler, in: Das George Orwell Lesebuch. Essays, Reportagen, Betrachtungen, Zürich 1981, S. 240-243; der Originalbeitrag dieser Rezension erschien am 21. März 1940 in der New English Weekly.

322 Ders., Die Diskriminierung Farbiger, in: Ebd., S. 217-219; der Originalbeitrag erschien unter dem Titel As I Please in der Tribune vom 11. August 1944.

323 Siehe ders., Antisemitismus in Croßbritanien, in: Ebd., S. 220-232; der Originalbeitrag erschien im April 1945 im Contemporary Jewish Record. Vgl. im Kontext der Auseinandersetzung mit dem Antisemitismus auch ders., Betrachtungen zur Judenfrage, in: Ebd., S. 233-235 (Rezension); der Originalbeitrag erschien am 7. November 1948 im Observer.

324 Hochgeschwender, Freiheit in der Offensive?, S. 113. Vgl. auch Horst Komuth, Manès Sperber, Arthur Koestler und Ceorge Orwell, Der Totalitarismus als Geißel des 20. Jahrhunderts, Würzburg 1987, S. 83 . 
Ende 1943 begann Orwell mit der 1944 fertiggestellten Fabel Animal Farm, ${ }^{325}$ die erst ein Jahr darauf erscheinen konnte, weil mehrere Verleger die Veröffentlichung ablehnten; unter anderem aufgrund der in dem Buch formulierten Kritik am alliierten Bündnispartner Sowjetunion. ${ }^{326}$ Seine Absicht bestand darin, dem in England in weiten Kreisen kursierenden unkritischen Russlandbild entgegenzutreten. Gleichwohl fühlte er sich »der politischen Linken zugehörig «. ${ }^{327}$ Mit seinem Hauptthema der »verratenen Revolution« wollte er zeigen, »dass die Sowjetunion, die weithin als sozialistischer Staat betrachtet und gefeiert wurde, sich in Wahrheit längst vom Sozialismus abgewandt hatte und dass in Russland die Macht von einer kleinen Schicht zu ihrem eigenen Nutzen ausgeübt wurde. Die Fabel sollte dazu beitragen, den Sozialismus aus seiner verhängnisvollen Identifikation mit Sowjetrussland zu befreien und wieder zu neuem Leben zu erwecken. « ${ }^{238}$

Nachdem die Zeitschrift Der Monat bereits die satirisch-politische Fabel Farm der Tiere im Verlauf des ersten Jahrganges in drei Teilen veröffentlicht hatte, ${ }^{329}$ begann die Redaktion Ende des Jahres 1949, Orwells (anti-)utopischen Roman 1984 abzudrucken. ${ }^{330}$ Erste Überlegungen zu dem Buch setzten bei Orwell bereits im Jahre 1943 ein. Beim Schreiben wurde er in erheblichem Maße durch drei Bücher beeinflusst: Borkenaus Der totalitäre Feind, Burnhams Das Regime der Manager und in Bezug auf die dargestellten Folterszenen durch Koestlers Sonnenfinsternis. In der Hochphase des Kalten Krieges kam vielen »Ideologen des Antikommunismus« nicht zuletzt in England, in den Vereinigten Staaten und in der Bundesrepublik Deutschland die Darstellung der totalitären Gesellschaft zupass, die das Buch politisch und ideologisch instrumentalisierten: ${ }^{331}$ zum einen in der Auseinandersetzung mit der Sowjetunion ${ }^{332}$ und zum

325 George Orwell, Animal Farm, London 1945 (dt. Ausg.: Farm der Tiere, Zürich 1946).

326 Howald, George Orwell, S. 104.

327 Ebd., S. 111.

328 Hans-Christoph Schröder, George Orwell. Eine intellektuelle Biographie, München 1988, S. 210.

329 Vgl. Der Hofstaat der Tiere. >Animal Farm<, in: Der Monat 1 (1949), H. 5, S. 38-54 (Teil I); H. 6, S. 10-24 (Teil II) und H. 7, S. 34-43 (letzter Teil), sowie die jeweiligen Einführungen der Redaktion.

330 Siehe die Veröffentlichung der insgesamt fünf Teile: »1984«. Ein utopischer Roman, in: Der Monat 2 (1949), H. 14, S. 115-137 (Teil I); H. 15, S. 239-277 (Teil II); H. 16 (1950), S. 357-391 (Teil III); H. 17, S. 485-521 (Teil IV) und H. 18, S. 570-602 (Teil V). Siehe hierzu auch die Buchrezension von Hellmut Jaesrich, Fünfunddreißig Jahre weiter ... Zu George Orwells neuem Roman »Neunzehnhundertvierundachtzig«, in: Der Monat 1 (1948), H. 11, S. 115-119. Die englische Originalausgabe erschien unter dem Titel Nineteen Eighty-Four (London 1949; dt. Ausg.: 1984, Zürich 1950). Vgl. auch John Strachey, Der unterdrückte Schrei. Koestler-Orwell -Whittaker Chambers, in: Der Monat 13 (1961), H. 150, S. 32-44. Von Orwell erschien im Monat noch ein weiterer Beitrag zu dem Thema »Armut und Hoffnung Großbritanniens « unter dem Titel Bericht aus London in: Der Monat 1 (1948), H. 3, S. 77-85, sowie eine kritische Auseinandersetzung mit Mahatma Gandhi in dem Artikel Gedanken über Ghandi. Zur vierten Wiederkehr seines Todestages (30. Januar 1948), in: Der Monat 4 (1952), H. 40, S. 357-363.

331 Zur Rezeption des Buches im Zeichen des Antikommunismus und zur frühen Verbreitung des Buches durch die amerikanischen Besatzungsbehörden in der Bundesrepublik - auch durch den Monat-siehe Bernd-Peter Lange, George Orwell: »1984«, München 1982, S. 9-16. Ich komme hierauf am Schluss der Untersuchung ausführlicher zu sprechen.

332 So war Golo Mann in seiner Buchbesprechung für die Frankfurter Rundschau vom 12. November 1949 der Auffassung, dass »1984« einerseits als Warnung zu betrachten sei und andererseits, dass es sicherlich primär von »kommunistischen Institutionen inspiriert sei, ohne jedoch diejenigen der Nazis und Faschisten zu übersehen. Und er beklagte, daß manche Amerikaner Farm der Tiere schon zur 
anderen, um jede sozialistische Politik als Gefahr brandmarken zu können. Gleichwohl entsprach es keineswegs der Intention und dem Selbstverständnis des Autors. In einem Brief an einen amerikanischen Gewerkschaftsfunktionär stellte er klar:

Mein letzter Roman ist NICHT als Angriff auf den Sozialismus oder die britische Labour Party (der ich nahestehe) gemeint, sondern als Bloßstellung jener Perversionen, zu denen eine zentralisierte Wirtschaft führen kann und die unter Kommunismus und Faschismus zum Teil schon Realität geworden sind. Zwar glaube ich nicht, das von mir geschilderte Gesellschaftssystem werde notwendig entstehen, doch bin ich der Meinung (wobei man nicht übersehen darf, daß mein Buch eine Satire ist), daß etwas Ähnliches kommen könnte. Außerdem glaube ich, daß totalitäre Cedanken schon überall in den Köpfen der Intellektuellen verwurzelt sind, und ich habe versucht, diese Gedanken bis zu ihrer letzten Konsequenz weiterzudenken. Der Schauplatz des Buches wurde nach England verlegt, um deutlich zu machen, daß die englischsprechenden Völker nicht von Natur aus besser sind als jedes andere Volk, und daß der Totalitarismus, wenn man ihn nicht bekämpft, überall auf der Welt triumphieren könnte. ${ }^{333}$

Darauf insistierte auch François Bondy in seinem Nachruf anlässlich des Todes von Orwell, dass nämlich von ihm in seinem letzten Buch »eine Synthese aller zum Totalitären neigenden Züge nicht nur Rußlands, sondern auch der angelsächsischen Welt geschaffen wurde ${ }^{334}$

Die große Rezeption und den Erfolg seiner beiden letzten Werke erlebte der an Tuberkulose erkrankte Orwell in einem körperlich sich ständig verschlechternden $\mathrm{Zu}$ stand. Nach einem weiteren achtmonatigen Aufenthalt in einem Sanatorium in Cranham wurde er im Herbst 1949 in ein Londoner Hospital verlegt, wo er ein zweites Mal heiratete. Wenige Wochen darauf verstarb Orwell am 21. Januar 1950 nach einer neuerlichen Lungenblutung im Alter von 46 Jahren. ${ }^{335}$

großen antikommunistischen Propaganda umfunktioniert und dergestalt die allgemeine Bedeutung des Buches ebenso gröblich entstellt hätten.«(Crick, George Orwell, S. 756)

333 Zit. n. ebd., S. 764 f.

334 François Bondy, Gentleman und Streiter, in: Der Monat 2 (1950), H. 18, S. 565-567, hier S. 565. Anlässlich der Veröffentlichung des ersten Teilabdruckes des Buches schrieb die Redaktion des Monat in den einleitenden Worten: »Der Ausgangspunkt seiner unerbittlichen Phantasie und seines blutigen Spottes ist seine Heimat - ein England, das auf der Bahn der Verstaatlichung und Bürokratisierung bedeutend weiter fortgeschritten ist, als es der englische Sozialismus von heute erwarten läßt, ein England, das durch die Preisgabe der persönlichen Freiheit, deren Hort es heute ist, seine eigenen Schwächen mit den Greueln von Faschismus und Stalinismus vereinigt. Orwell erreicht damit, seine Leser vor jeder erdenklichen Form des Totalitarismus abzuschrecken, obwohl er die Entwicklung zu dem teuflischen Staat des Jahres 1984 fast als etwas Unabwendbares darstellt.« In: Der Monat 2 (1949), H. 14, S. 115.

335 Kurz vor seinem Tod erstellte Orwell für Celia Kirwan, die Zwillingsschwester von Koestlers Frau und Mitarbeiterin einer Abteilung des britischen Außenministeriums, dem »Information Research Department«, die zuständig war für antikommunistische Propaganda, für ebendiese Abteilung eine 35 Namen umfassende Liste von Künstlern, Schauspielern und anderen Intellektuellen, die Sympathien für die Sowjetunion hegten und die er als »Kryptokommunisten« bzw. »fellow travellers« verdächtigte. Das Ziel bestand darin, der schleichenden sowjetischen Unterwanderung der westlichen Staaten entgegenzutreten. Orwell nannte als »Verdächtigte« u. a. die Historiker Carr und Taylor, den Dichter Stephen Spender, den Filmregisseur Orson Welles, den irischen Dramatiker 